\title{
LAS PUERTAS Y EL TIEMPO ${ }^{1}$
}

\author{
María Eugenia López Aguilera \\ Universidad de Chile \\ meugenialopez@gmail.com
}

\section{INTRODUCCIÓN}

He llegado a este tema por simple curiosidad hacia algunas costumbres de las sociedades más tradicionales en los llamados "ritos de tránsito" y, en especial, aquellos ritos de hospitalidad que involucran el acto de traspasar una puerta de una casa cualquiera. Este acto es aprobado por quien recibe al visitante para que éste ingrese a su mundo de pertenencia, donde está lo privado y lo familiar. El hogar es el templo para la familia o los individuos que allí viven. Por ello, al venir a este sitio un nuevo individuo se le invita a conocer y compartir lo íntimo y privado de prácticas y costumbres familiares que se le comunican al visitante para que forme parte de ellas. La privacidad del hogar es cuidada y mantenida mediante una puerta que la separa de lo público. Lo público es lo que compartimos con los demás individuos de nuestra sociedad: calles, mercados, comercio, edificios públicos, parques, barrios etc... Lo importante de este rito de hospitalidad es que lo encontramos aún hoy en el acto de ingreso a un espacio, sea éste civil o religioso; si se nos permite entrar a una residencia o a un templo cualquiera, debemos tener en consideración costumbres y actitudes muy particulares que deberán ser anteriormente informadas para no transgredirlas.

Cualquiera que sea la puerta por donde debemos pasar, muy internamente se experimenta un sentimiento hacia aquel otro espacio que guarda y protege dicha puerta. Es el misterio que encierra el cambio de un espacio a otro, de un mundo y de un concepto de vida. Y aquí he tratado de reflexionar sobre el primero de los elementos con que nos encontramos en

\footnotetext{
${ }^{1}$ Publicado en VIII Jornadas Interdisciplinaria de Religión y Cultura. Páginas 123 - 134
} 
este maravilloso mundo de los espacios profanos y sagrados: las puertas.

\section{LAS PUERTAS... ¿CÓMO Y QUIÉNES SON?}

La puerta es el elemento fundamental que contiene en sí la función delimitadora de un espacio y un tiempo en particular. Sin ella el espacio no existiría; el espacio requiere de un "umbral" por el cual se pueda tener acceso a ese otro espacio. El tiempo se encuentra presente desde el pasado impreso en la materia sea esta de piedra, mármol, granito o simplemente madera. El tiempo queda, como un sello inviolable, sujeto a la forma y en el estilo del pasado y de toda la carga estético-plástica que poseyeron quienes lo diseñaron y lo hicieron. Tiempo transformado en forma, tiempo detenido y atrapado en una piedra como testimonio para el futuro.

La piedra, forma y el diseño, respectivamente, se tomarán como base de este análisis de algunas puertas o pórticos más representativos para la confirmación de la hipótesis recién planteada.

Según Manfred Lurker "la puerta posibilita o impide el paso según esté abierta o cerrada. Con puerta y portón se une la idea del umbral entre dos ámbitos, el exterior y el interior, el hoy y el mañana, lo profano y lo sagrado” (1994, p.182).

En el lenguaje de los mitos y religiones del antiguo Oriente se habla de las puertas del cielo y del mundo subterráneo; abandonar este mundo es "entrar" en el más allá.

"La idea de una puerta entre el más acá y el más allá era también familiar en el pensamiento bíblico" (Lurker, p.182).

Las puertas -espacio grande o pequeño, privado o público, habitación o pasillo, purificación o condenación. Divide espacios, señala poderes, atributos (lo sagrado de lo profano, lo superior de lo inferior) en categorías y estratos (el jefe de la secretaria, el dueño de los clientes, el juez del acusado, etc.). 
En cuanto a los materiales que se emplean en su hechura, encontramos puertas "para siempre" y puertas "de siempre" y aquellas otras que son "para ahora" o "por ahora", donde sus materiales varían según importancia y función.

Por otra parte es necesario considerar el factor formal: lo curvo versus lo adintelado. Lo "insistido", como archivoltas y remarcaciones, y lo "sutil" o escondido, como aquellas puertas secretas, esas que se mimetizan con el entorno y que esconden el paso a un mundo y espacio encubierto o clandestino. Puertas que utilizan el arco de medio punto han sido consideradas como puertas que remiten el paso solemne de personajes o figuras de importancia y se les asocia a un sentido extraterrenal. El arco es un espacio curvo que se asemeja a la bóveda celestial. Por lo anterior, encontramos que se han empleado en algunos tipos de puertas de sitios destinados a cultos religiosos y en algunos edificios de importancia como palacios y casas de gobierno. El arco de medio punto en su desplazamiento en línea recta construye un espacio abovedado, forma que, a quien transite por él, le confiere un sentimiento atado a la idea de lo infinito, lo superior, de lo divino y celestial. Ejemplo de ello son las construcciones del románico que bien reflejan ese valor expresivo del espacio donde se establecen diferencias entre lo profano, lo de tránsito y los espacios sagrados.

En algunas abadías o monasterios del románico hoy podemos entender este problema mediante la decodificación del tipo de espacio: los espacios profanos están definidos mediante el uso del dintel y de los cielos rectos reforzados con el uso del artesonado en madera policromada. Muy diferente es cuando ingresamos a un espacio sagrado, es una puerta de arco que nos ubica en un espacio abovedado, con refuerzos de arcos fajones y nervaduras que embellecen y acentúan lo circular de los cielos.

De la puerta de arco muchas otras se derivan en función de reforzar la idea que ya he señalado aquí; quizás se aumente la imagen de lo importante, inalcanzable o elegante mediante algunos elementos decorativos añadidos a la concepción de origen. Podríamos entonces mencionar los espacios que entregan las puertas góticas con sus infinitas variaciones del arco ojival de altas y estilizadas bóvedas de aristas en su interior. 
Opuesta es la concepción de espacio que entregan aquellas puertas adinteladas que en su prolongación en línea recta extienden un tipo de espacio rectangular. Por sobre nuestras cabezas este espacio se delimita en sí mismo con la fuerte presencia de la línea horizontal, es la idea de lo finito, de lo terreno y de lo real.

PUERTAS QUE CONOCEMOS, SENTIMOS, DE LAS QUE HABLAMOS Y DE LAS QUE NO

Finalmente -y como punto central de este ensayo- no es posible olvidar aquel concepto que poseen las puertas y repercuten en nuestro espíritu y en nuestro comportamiento: las puertas de espera, de tránsito pausado o de tránsito fugaz y rápido. Las puertas del poeta imaginarias y metafóricas- y de las que aún andamos en búsqueda, como las puertas de la gloria, puertas del perdón, de la muerte, del infinito, de la eternidad, del amor o de la agonía, del infierno, de América... Otras patéticamente poéticas, como las puertas del abismo o al abismo, a lo oscuro, a lo subterráneo, que nos transportan a mundos ocultos, maléficos, inquietos y donde reina el caos. Las hay algunas de carácter divino, como las puertas del Cielo o al Cielo, que nos transportan a un sitio por sobre nosotros, a mundos de luz, infinitos, donde reina la paz, la perfección, el equilibrio y donde sus protagonistas viven en una dimensión inmaterial y celestial.

Hay puertas por las que pasamos siempre, las que ni siquiera miramos, son aquellas de todos los días, que no significan, nada tienen para recordarlas porque son anónimas. $\mathrm{Su}$ traspaso no implica un cambio de actitud en nosotros, su tránsito no nos repercute, el mundo que nos muestran es conocido, indiferente y cotidiano.

Otras puertas nos impresionan por su forma, por su textura y diseño. Pasar a través de éstas nos significan un logro de acceso a un sitio con significado e importancia. Son muy diferentes unas de otras, tienen nombre, autor, categoría, personalidad e identidad inconfundibles. Pasar por éstas nos lleva a sitios con tiempo y espacio llenos de significados y 
misterios. Son también de este grupo aquellas puertas que solo se abren en algunas oportunidades muy especiales, como las "puertas santas", sagradas, de palacio, basílicas.

En cuanto a nuestra relación con las puertas podríamos decir que algunas "reciben" y otras "despiden", unas "invitan" y otras cortan o impiden un tan gratuito paso como aquellas del claustro, de hospitales, cárceles, áreas militares...

De igual forma están las puertas con celosías, puertas celosas, celestinas, fisgonas, de tímidos y descarados observadores, que guardan secretos y mensajes amorosos entre susurros clandestinos. Las mismas que cobijan a jovencitas casaderas, a las de Bernarda Alba de Lorca, las del convento de Doña Inés del Tenorio, las del harén de la Alhambra y las de Doña Ximena, la del Cid, y en viejas tabernas y prostíbulos. Puertas de santas mujeres e igualmente de las que no lo son o no lo parecen tanto.

\section{LAS PUERTAS, SU ESPACIO Y SU TIEMPO QUE HACEMOS NUESTROS}

El traspaso de la puerta nos produce una experiencia kinestésica importante con el espacio; podemos entender lo que es exterior y lo interior. Hay un valor emotivo que puede estar implícito en esta acción, donde juegan algo de misterio, de magia y factor sorpresa, sobre todo cuando estos dos ámbitos son muy opuestos. Espacios que cuentan de un antes y un después, de un fuera desde donde venimos con nuestra historia y tiempo, y que al traspaso del umbral pasamos a integrarnos a la historia de ese nuevo espacio, el cual se activa en el preciso momento en que ingresamos, se nos vuelve real, con vida, aroma, luz, temperatura y protagonistas que hablan de sus vidas desde el pasado. Aquí ya entramos en el juego envolvente del tiempo como experiencia dentro del espacio arquitectónico, podemos ahora observar al tiempo como huella de quienes y desde cuando realizaron esta puerta o este nuevo espacio expresado en las lecturas del estilo, material, temas, policromía, formas, texturas y la importante pátina del tiempo que deja su huella en cada uno de estos aspectos.

En lo que se refiere a la percepción del espacio, Sven Hesselgen nos enseña cuán 
importante es vivir la experiencia del espacio arquitectónico, pues esto es un cúmulo variado de percepciones y de sensaciones entendidas y sentidas solo en el sitio mismo, allí donde se hacen realidad. Esto nos recuerda a Boring, pues los llama "criterios de profundidad" que nos dan la "tercera dirección", el "sentido áptico" que nos revela aquello que es cerca y lo que está más lejos en un espacio interior. También entra el juego del tacto, sentido fundamental para el conocimiento de un espacio o de un objeto, pues cuando tocamos las paredes y las cosas en un espacio nos posibilita de inmediato el tener la idea de su consistencia material, su temperatura, la misma temperatura que envuelve a ese espacio, pues procede de la materia y del entorno que le rodea. Mediante la temperatura y el movimiento del aire de un espacio o habitación se nos manifiestan muchísimos datos acerca de dónde nos encontramos. Y lo auditivo aquí cobra su función importante pues un eco o una reverberación larga nos señalan cuán grande es un espacio y por lo contrario un corto eco o una pequeña reverberación dicen de cuan pequeño es nuestro espacio. Estos dos elementos -eco y reverberación- nos ubican en distancia y dirección, porque por donde desaparece un eco o se extiende y pierde una reverberación es señal por donde se amplía ese espacio.

\section{¿Y EL TIEMPO?...}

No es posible hablar de espacios si no hemos de tomar en cuenta al tiempo, pues ambos son las condiciones esenciales del estado corporal, condición del hombre en la tierra. Ambas condiciones definen en este estado la finitud y de ambas la más espectacular es el tiempo. Pues es el tiempo que se va perpetuando en los cuerpos y le pone distancia a ese tiempo de creación. F. Schuon nos define esto como "El tiempo es la contingencia que mina las cosas... la decadencia que aleja del origen (adámico)”.

Vivir en el tiempo es en verdad un salirse del ser, del centro divino y acercarse a los bordes, a los límites donde nos encontramos con dos caminos, es una vía doble que nos conduce hacia el Creador o hacia el Mal. El encuentro este se llevará a efecto fuera del tiempo. Y 
para lograr salir del tiempo debemos romper totalmente con lo terrenal y ubicarnos en aquel estado puro primigenio del que gozábamos antes del pecado original, pues allí en el Paraíso no existía el tiempo y todo permanecía en un estado de creación, de génesis y donde el tiempo no estaba considerado. Solo existía un Hoy para siempre. Con el pecado de Adán y Eva comienza la cuenta irreversible del tiempo en nuestro mundo y en nuestras vidas, todo se hace pasajero, todo discurre y trascurre en un lapso y cuentas de épocas, tiempos, eras y períodos. La medida temporal es necesaria para ubicarnos nosotros, para reconocer las cosas creadas por la humanidad dentro de un lapso de historia. Y es aquí donde nos encontramos parados hoy, reconociendo y apreciando al tiempo en nuestras protagonistas, las puertas, pues ellas son esos signos que nos pueden revelar espacios y tiempos desconocidos y hermosos.

No hay posibilidad de confundimos frente a esta carga de datos testimoniales, historias de fe, poderío, devoción y pasión. Arquitectos, artistas y artesanos crearon estos enormes trozos de piedras, tallaron, moldearon figuras que dan su nombre y tiempo. Poseían éstos la increíble tarea de otorgar a todo ello una identidad que aún con el transcurrir de los siglos es imposible perder, donde el tiempo fue atrapado para la contemplación y comprensión de quienes muchos siglos después aún seguimos alucinados con esta mágica acción de traspasar umbrales de muchas puertas, para conocer sus historias y sus misterios allí guardados.

Encontramos al tiempo expresado en dos dimensiones:

1. El estilo nos habla de un tiempo de creación, de hechura y de los orígenes o influencias. Ejemplo: Un pórtico románico se le ubica en el tiempo según su ornamentación. Mientras más simple sea la decoración su data es más temprana (h. 900 a 1100 d. C.) y si posee algunas lacerías en sus jambas o archivoltas entenderemos la influencia y /o trabajo de artesanos mudéjares o con influencia árabe. Y si a este mismo tipo de pórtico lo encontramos en alguna ciudad de América hispana podríamos deducir la fuerte influencia y su data debiera ser muy posterior al anterior y los análisis de sus ornamentaciones y materiales nos darían fechas más cercanas a su creación, tal vez siglo XVII o XVIII. 
2. El material registra el pasar del tiempo marcando suave o gravemente huellas en la superficie de la estructura que podemos comprobar mediante la observación de marcas. Viento y lluvia relamen texturas, destiñen y descascaran colores, pátinas y barnices hasta despojarla y mostrar desnuda la piedra, cal o madera. La humedad y la sal de aquellos lugares vecinos al mar se perpetúan en mordiscos en los perfiles de las más robustas estructuras milenarias de hierro, en las pequeñas mirillas, cerrojos y bisagras confesando sin piedad años y siglos de muda existencia.

Del mismo modo el hombre en su diaria relación con las puertas ha sido instrumento del tiempo dejando pequeñas señas en su superficie y estructura e incluso su entorno. En el color observamos la pátina del uso en los contornos de las manillas, de los bordes donde las manos se posan muchas veces al día para abrirla, los bordes de pasada se han hecho de perfiles angulosos a suaves y curvos, porosas y relamidas superficies con miles de pequeñas huellas.

\section{LAS PUERTAS SAGRADAS}

Al templo lo tenemos como imagen del mundo sagrado y es esa puerta la que nos permite el ingreso a este terreno. En Génesis 28:17 se nos advierte a la llegada: “iQué temible es este lugar! No es sino la casa de Dios y la Puerta de los cielos". Juan 10:7/9, nos dice que el mismo Jesús se denomina como la puerta: "Yo soy la puerta: el que por mí entrare se salvará”. De aquí la importancia enorme de las puertas de los templos, consagradas por medio de una acto ritual, ungidas con santo crisma en cada una de sus jambas junto a las palabras del obispo o pontífice: "Que ésta sea bendita, consagrada... que sea una entrada de salvación y de paz; que sea una puerta de paz, de la intercesión de Aquel que se denominó a sí mismo La Puerta, por N.S.J.C. Amén”.

Si nos encontramos con un recinto sagrado frente a nosotros entendemos que es la puerta la que nos separa de lo profano a Jo sagrado. Ese vacío o cesura que es la puerta misma tiene 
el poder de que a través de ella podemos pasar de nuestro mundo al espacio y pertenencia de lo sagrado.

Quienes han visto o visitado algunas iglesias románicas o góticas pueden apreciar la importancia concedida a la decoración de sus puertas y sobre todo al pórtico principal, donde variados tipos de ornamentaciones enfatizan el significado de dicha entrada. En el, un espacio al cual llamaremos nicho reproduce el conjunto del edificio. Igual función cumplen el arco, la bóveda y la cúpula que tienen al cielo como significado. Diferente es lo adintelado que, como rectángulo de base, se relaciona con lo terrenal.

Es aquí en la puerta donde se lleva a cabo una teofanía; ya lo dijo T. Burchardt: "la puerta es un resumen de todo el templo representado en un nicho de base rectangular rematado por un arco de medio punto o mitral”. Es lo que se llama símbolo de la Caverna cósmica, aún vigente en la India o en el Islam por el mihrab de las mezquitas, y más aún esta idea resalta en la bóveda del tímpano del pórtico de las iglesias bizantinas y románicas y a cuyo abrigo resplandece triunfalmente la imagen del Pantocrátor que preside, recibe y bendice en esta entrada al templo.

Así podemos entonces entender que el pórtico de la iglesia románica es sobre todo una representación en piedra de aquella visión del cielo abierto, de la puerta abierta en el cielo percibida por San Juan Evangelista, en Apocalipsis 4,1. Por ello, es una de la expresiones plásticas más sorprendentes de lo que es el espíritu mismo del cristianismo, es su sentido escatológico, espera de la Parusía, la vuelta de Jesús. Esta idea se hizo aquí piedra, para que el fiel al entrar en este templo tenga frente a sí una visión global del mundo que le espera y se le manifiesta. Aquí en la puerta se encuentra gráficamente resumida la manifestación de fe: "Aquel que era, es y vendrá".

\section{LA ORNAMENTACIÓN DE LOS PÓRTICOS DE LAS IGLESIAS CRISTIANAS}

Encontramos en los pórticos de las iglesias cristianas dos tipos de simbolismo: el cósmico y 
el místico, que no se excluyen sino que se apoyan y complementan. En el tímpano hallamos la imagen de Cristo en majestad o en gloria y corrientemente inscrito en la escena del Apocalipsis, la Ascensión o la Transfiguración. En la archivolta -que rodea al tímpano- se decoran los montantes y el friso vegetal, representando una estilización del Árbol del Mundo, símbolo ancestral de la humanidad, igual que en la India. En el templo cristiano este árbol es una vid, concepto simbólico de Cristo. También dentro de este espacio hallamos el crismón, símbolo de cruz inscrita en un círculo o el monograma de Cristo, también dentro de un círculo que es la representación de la idea que alude a la rueda cósmica, esquema del mundo y del movimiento cíclico. En el crismón seis brazos nos indican las seis direcciones de los puntos cardinales y los ejes polares con las letras "P" y "X" unificadas a propósito en un solo plano. Al crismón y al monograma solemos encontrarlos grabados en los relieves de los dinteles de la mayoría de las puertas carolingias y así, unidos al oculus oriental, dieron nacimiento al rosetón, elemento éste donde más se acentúa el concepto de la rueda cósmica por los 12 radios que posee, con medallones a su alrededor, símbolos del zodiaco y en ocasiones de los 12 apóstoles. Al centro de todo lo anteriormente descrito suele también aparecer en el pórtico un cubo estático cuyo espacio interior lo ocupa la imagen del Cristo en majestad. Sobre esto Patrick Négrier reconoce el simbolismo cósmico que poseen los rosetones y la relación que éstos tienen con la rueda cósmica o del tiempo y el recorrido de las constelaciones, pero también nos añade que ha encontrado otros símbolos tallados en la piedra, llamados arquitecturales y que remiten a conceptos no solo religiosos sino que son un resumen del aporte cultural de las civilizaciones. Son éstos:

a) el laberinto = a Creta y su palacio Cnossos;

b) la Torre de Babel = a los zigurats mesopotámicos;

c) la Pirámide = a Egipto;

d) el Templo de Salomón = al templo judío o israelita; 
e) la Tumba = a las tumbas de los santos de las primeras basílicas;

f) la Catedral = a la arquitectura gótica;

g) el microcosmos humano situado entre una escuadra y un compás y supuestos

a una estrella inscrita en un círculo = derivados a los modelos análogos

elaborados por Leonardo da Vinci y Henri-Corneille Agrippa de Nettesheim, a la arquitectura renacentista.

Durante el período gótico a las tres puertas de los frentes de las iglesias que acompañaban a1 rosetón se les agrega una gran moldura inspirada -según dice Hamann Mc.Lean- en aquellos arcos de triunfo romanos que reúnen características similares de tres puertas con moldura como remate superior.

El frente con el gran pórtico es en sí un arco triunfal convertido en aquella puerta celeste, el esplendor de la janua coeli.

En la práctica, las iglesias muestran solo tres puertas: al Oeste (entrada), al Norte y al Sur. Aquella del Este fue reemplazada por otro concepto de abertura que son las grandes vidrieras del ábside, receptoras del sol naciente y transformadas en sorprendentes puertas solares. Las vidrieras o vitreaux aparecen distribuidas de tres por lado, correspondiendo a los signos del zodíaco, cada grupo de tres a una estación del año y a los ejes cardinales, respectivamente.

Otros elementos simbólicos presentes en la puerta y en los pórticos de las iglesias y templos cristianos son: el Tetramorfos, esos cuatro vivientes misteriosos que rodean a la figura de Cristo en majestad. Esto es de la visión de Ezequiel (1/5-14) y de San Juan en el Apocalipsis y se les designa como los 4 ángulos o pilares del mundo, 4 elementos constitu- 
tivos de la naturaleza y, en la tradición judía, a cada una de las letras del nombre divino: YHWH donde $\mathrm{H}=$ león, $\mathrm{W}=$ toro, $\mathrm{H}$ = águila. También corresponden a este número los evangelistas que son la revelación de los cuatro pilares cósmicos y tal es su importancia en la representación al interior de los templos que, en algunas cúpulas antiguas aún se observa a la representación de Cristo al centro sostenido por las figuras de los 4 evangelistas con sus símbolos, situados en las cuatro trompas de las cuatro esquinas.

Una vez que traspasamos el umbral y dejamos tras de nosotros la puerta, la sacralidad del tránsito y de la puerta adquiere su máximo valor cuando se trata de un templo. Es por esto que se colocaban en la entrada de los edificios sagrados a los llamados guardianes del umbral: estatuas de arqueros, dragones, leones o esfinges, personajes divinos o semidivinos, como el Jano de los romanos que es el dios de la puerta - janua, y del primer mes del año. Es el dios que abre el año, januarius. Estos guardianes tenían como tarea recordar a quienes se disponían entrar, el serio sentido del paso que se daba al ingresar al recinto sagrado. Una inscripción que se encuentra en la Iglesia de Mozat nos la recuerda: “Tú que entras, vuélvete hacia el cielo”. El recinto sagrado nos separa del mundo profano porque él es un lugar santo y la puerta es una cesura que posee el prodigio de transportarnos a ese mundo sagrado.

\section{LA HISTORIA NOS CUENTA DE OTRAS PUERTAS Y EN OTROS TEMPLOS}

Los templos egipcios nos impresionan desde la lejanía por su imponente presencia materializada de la piedra. Het Neter, es decir, palacio de dios y también Per Neter o casa de dios, considerándosele entonces el sitio donde habita la divinidad, por mediación de la estatua de culto y se presenta en relación con los hombres. La masa monumental de la entrada con la puerta principal flanqueada por dos enormes construcciones de forma troncopiramidal -los pilones que nos recibían (en el pasado) con cuatro enormes mástiles que sostenían oriflamas y que simbolizaban la pareja de diosas Isis y Neftis, guardianas de Osiris, quienes cuidaban el dios que residía en el sanctasanctórum. Las fachadas exteriores 
e interiores estaban completamente policromadas con vivos colores.

Sobre los templos griegos señala el investigador René Guénon que

"el mejor arte griego y, especialmente la arquitectura de los templos, era una especie de psicagogia que conducía al mundo exterior, buscando cobrar conciencia de la inmanencia de lo divino en el mundo visible, y ello mediante la armonía al propio tiempo que las relaciones entre el hombre, el mundo y la divinidad".

Esta es la fórmula de todo arte sagrado, pero en la arquitectura griega posee ese especial aspecto de haber comprendido la belleza en cuanto reflejo de lo divino en lo visible, en la forma matemática como número y proporción, ambas realidades sobre la que se basan todos los aspectos del logos en cuanto intelecto superior y razón. Templos griegos donde la geometría es también filosofía y teología hechas piedras. La armonía se hace eco en las proporciones de sus volúmenes, en ritmos astronómicos y también biológicos. Relación amorosa entre el universo vivo, plenamente presente, y el hombre. Esta euritmia tenue coincide hasta con la música, por lo que no peco en decir que "el templo griego es música hecha piedra", como lo dijera Georgiades en su obra La armonía en la composición arquitectónica (1926).

La entrada como puerta está marcada por la sencilla y armónica presencia de las columnas que soportan a frisos, triglifos y metopas horizontales, sobre las que se levanta el triangular frontón con bellas formas esculpidas y policromas que nos hablan de acciones y poderes de los dioses. A ello Guenón le reconoce como "imagen del cielo que responde a la elevación de los hombres hacia él" (Hani:1999, p.208). Generalmente el tímpano se pintaba en azul y en otras, rojo. Un triángulo puesto sobre el cuadrado de la fachada de columnas, el tres de lo divino que refuerza la cuadratura de lo terrenal. En el traspaso de las columnas, la transparencia de lo exterior tamiza el paso. Más al interior está la cella, que guarda tras sus paredes blancas a la divina imagen. Es un paso gradual, sencillo, pero a la vez imponente y sublime que ya han anunciado las verticales de las columnas que como flechas nos indican el cielo, el mundo de los dioses, terreno divino hacia donde nos dirigimos al venir hasta aquí. 
Como templo islámico está la mezquita, y se nos hace presente ya en la lejanía mediante sus brillosas cúpulas teñidas de color dorado, rodeada de minaretes. Construcción octogonal que sostiene a la gran cúpula central. Su decoración nos transporta al concepto de sitio sagrado, lugar de unión con Dios-Alá por la presencia de azulejos con frases del Corán, la revelación a Mahoma. Las puertas islámicas refuerzan y remarca la presencia de ésta en su forma. El arco de herradura enjutado (exsuctus quiere decir agotado) o él polilobulado se decoran por el exterior e interior con yeserías de diseños geométricos o vegetales. Los exteriores suelen ser bastante austeros en relación con los interiores abigarrados de formas y colores, el "horror al vacío" decorativo propio de estos pueblos originarios del desierto monocromo en relación con el azul del ciclo. Paisaje bicromo, falto de texturas visuales y policromas de los sitios fértiles como los del soñado paraíso que se asemeja a un refrescante y verdoso oasis. El templo es un oasis, como también lo son sus casas y palacios. Por todo lo anterior es que la importancia en la decoración de sus interiores nos impresiona y sentimos muy fuertemente aquella idea de diferenciar lo exterior de lo interior.

\section{CONCLUSIÓN}

En este pequeño y corto viaje por sitios y tiempos diferentes donde no hemos hecho más que hablar de las puertas, solo he pretendido buscar al espectador ensimismado y deslumbrado y que ojalá nunca desistiera de tomar unos breves minutos de su existencia para compartir con la humanidad esos trozos de tiempos y de espacios -las puertas- que desde el pasado aún se asoman y guardan misterios que aún desean compartir con nosotros para contamos sus vidas y lo que fueron en el pasado y lo que van siendo en el presente. Las puertas son como nosotros mismos, cada una con su belleza, sus adornos, personalidad, historia y protagonismo. Abrid una puerta y se abrirá un mundo nuevo para vosotros. 


\section{BIBLIOGRAFÍA}

\section{Campos Payo, Juan}

Esto es Toledo, Artes Gráficas Toledo S.A., Toledo, 1982.

De Pedro, Aquilino

Diccionario de términos religiosos y afines, Editorial Verbo Divino, Ediciones Paulinas. Madrid 1993.

Hani, Jean

Mitos, Ritos y Símbolos: los caminos hacia lo invisible, Ediciones Sophia Perennis, Barcelona, 1999.

Hesselgen, Sven

El Lenguaje de la Arquitectura, 1973.

Morante López, Felisa y Ruiz Zapata, Ana María

Análisis y Comentario de la Obra de Arte, Iniciación Universitaria EDINUMEN Editorial, Madrid 1997. 
Muller, Werner y Vogel, Gunther

Atlas de Arquitectura l. Generalidades. De Mesopotamia a Bizancio, Alianza Editorial, Madrid 1997.

Niégricr, Pátrick

El Templo y su simbolismo, Compás Ediciones, Madrid 1998.

Otros

López Aguilera, María Eugenia

Registros de viajes de los años 1983 - 1989- 1992 y 2000 y Archivo fotográfico personal. 